\title{
CrystEngComm
}

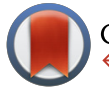

CrossMark $\leftarrow$ click for updates

Cite this: CrystEngComm, 2016, 18, 1825

Received 24th December 2015, Accepted 2nd February 2016

DOI: $10.1039 / \mathrm{c} 5 \mathrm{ce} 02540 \mathrm{k}$

www.rsc.org/crystengcomm

\section{Solvothermal synthesis of coordination polymers at different temperatures and their luminescence studies $\uparrow$}

\author{
Sanchari Pal, Tapan K. Pal and Parimal K. Bharadwaj*
}

\begin{abstract}
A new linker, [1,1':2',1'-terphenyl]-4',5'-dimethoxy-4,4"-dicarboxylic acid $\left(\mathrm{H}_{2} \mathrm{~L}\right)$ has been used along with 4,4'-azobispyridine (azpy) as the co-linker to solvothermally synthesize six coordination polymers (CPs). These compounds are formulated as $\left\{\left[\mathrm{Zn}(\mathrm{L})(\text { azpy })_{0.5}\right] \cdot\left(0.5 \mathrm{H}_{2} \mathrm{O}\right)\right\}_{n}(1),\left\{\left[\mathrm{Zn}_{2}(\mathrm{~L})_{2}(\text { azpy })\right] \cdot(\mathrm{DMF}) \cdot\left(1.5 \mathrm{H}_{2} \mathrm{O}\right)\right\}_{n}(2)$, $\{[\mathrm{Zn}(\mathrm{L})(\mathrm{bphy})] \cdot(\mathrm{DMF})\}_{n}$ (3), $\left[\mathrm{Cd}(\mathrm{L})(\text { azpy })_{0.5}(\mathrm{DMF})\left(\mathrm{H}_{2} \mathrm{O}\right)\right]_{n}(4),\left\{[\mathrm{Co}(\mathrm{L})(\operatorname{azpy})]\left(2 \mathrm{H}_{2} \mathrm{O}\right)\right\}_{n}$ (5) and $\left\{\left[\mathrm{CO}_{3}(\mathrm{~L})_{2}(\mathrm{bphy})_{2^{-}}\right.\right.$ $\left.\left.(\mathrm{HCOO})_{2}\left(\mathrm{H}_{2} \mathrm{O}\right)_{2}\right](6 \mathrm{DMF})\left(6 \mathrm{H}_{2} \mathrm{O}\right)\right\}_{n}(6)$ (bphy = 1,2-bis(4-pyridyl)hydrazine). Interestingly, 1 and 2 which are synthesized at 90 and $120{ }^{\circ} \mathrm{C}$, respectively, are found to be orientation isomers. When the solvothermal reactions are carried out at $140{ }^{\circ} \mathrm{C}$, the azo-bond in the co-linker azpy is reduced to bphy as found in 3 and 6. All the complexes exhibit an sql topology. They are characterized by X-ray crystallography, elemental analysis, thermogravimetry, powder X-ray diffraction and infrared spectroscopy. Solid state photoluminescence studies show an intra-ligand $\pi-\pi^{*}$ transition in each case.
\end{abstract}

\section{Introduction}

The design and synthesis of coordination polymers (CPs) have acquired an explosive growth in recent years due to not only their fascinating architectures but also their potential applications in different contemporary fields. ${ }^{1-7}$ Synthesis of these materials demands designing of new linkers that can be combined with the coordination tendencies of the metal ions. ${ }^{8,9}$ Interestingly, temperature, solvent, concentration, $\mathrm{pH}$ of the medium and templating molecules (ions) can greatly influence the ultimate structure of these materials. ${ }^{10-13}$ Particularly, temperature can play an important role during synthesis, by influencing the rate of crystal growth and the final structure. ${ }^{14,15}$ Predictability of the resultant structure becomes very difficult when the linker can adopt more than one conformation. ${ }^{16,17}$ On the other hand, in situ generation of new ligands ${ }^{18}$ during the solvothermal synthesis as well as framework isomerism ${ }^{19-24}$ has added another dimension in the synthesis of new architectures.

Herein, we report a new V-shaped linker, $\left[1,1^{\prime}: 2^{\prime}, 1^{\prime \prime}\right.$ terphenyl]-4',5'-dimethoxy-4,4"-dicarboxylic acid $\left(\mathbf{H}_{2} \mathbf{L}\right)$ which solvothermally forms six different coordination polymers

Department of Chemistry, Indian Institute of Technology Kanpur, Kanpur-208016, India.E-mail: pkb@iitk.ac.in

$\dagger$ Electronic supplementary information (ESI) available: Synthesis of the ligands and their ${ }^{1} \mathrm{H},{ }^{13} \mathrm{C}$-NMR, mass spectra, X-ray crystallographic data in CIF format, table for selected bond distances and angles for complexes 1-6, complete data for IR, PXRD, TGA analysis, and additional crystal structures. CCDC 1437804 (1), 1437805 (2), 1437806 (3), 1437807 (4), 1437808 (5), 1437809 (6). For ESI and crystallographic data in CIF or other electronic format see DOI: $10.1039 / \mathrm{c} 5 \mathrm{ce} 02540 \mathrm{k}$ when used with the co-linker 4,4'-azobispyridine (azpy) (Scheme 1). The co-linker has interesting structural features for studying optical and redox properties. ${ }^{25}$ Besides, the possibility of its in situ reduction ${ }^{26-31}$ to 1,2-bis(4pyridyl)hydrazine (bphy) offers another route to synthesize new compounds. We report the successful synthesis of six new CPs and their photoluminescence properties at room temperature in solid state as well as in dispersed medium.

\section{Experimental section}

\section{Materials and measurements}

Reagent grade 1,2-dimethoxybenzene, $\mathrm{PdCl}_{2}, \mathrm{Zn}\left(\mathrm{NO}_{3}\right)_{2} \cdot 6 \mathrm{H}_{2} \mathrm{O}$, $\mathrm{Cd}\left(\mathrm{NO}_{3}\right)_{2} \cdot 4 \mathrm{H}_{2} \mathrm{O}$, and $\mathrm{Co}\left(\mathrm{NO}_{3}\right)_{2} \cdot 6 \mathrm{H}_{2} \mathrm{O}$ were obtained from Sigma-Aldrich and used as received. All solvents were procured from S. D. Fine Chemicals, India and they were purified following the established methods prior to use. Characterization of the linker and the co-linker were carried out by a number of spectroscopic techniques as detailed<smiles>COc1cc(-c2ccc(C(=O)O)cc2)c(-c2ccc(C(=O)O)cc2)cc1OC</smiles>

$\mathbf{H}_{2} \mathbf{L}$<smiles>c1cc(N=Nc2ccncc2)ccn1</smiles>

azpy
Scheme 1 Schematic diagram of the linker $\mathrm{H}_{2} \mathrm{~L}$ and co-linker azpy. 
previously. ${ }^{32}$ Powder X-ray diffraction (PXRD) patterns of the compounds were recorded on a Bruker D8 Advance diffractometer equipped with nickel-filtered $\mathrm{CuK}_{\alpha}$ radiation. Thermogravimetric analyses (TGA) $\left(5{ }^{\circ} \mathrm{C} \mathrm{min}^{-1}\right.$ heating rate under nitrogen atmosphere) were performed using a Mettler Toledo Star System. The solid-state emission spectra were recorded using a Jobin Yvon Horiba Fluorolog-3 spectrofluorimeter at room temperature (RT). The UV-vis spectra were recorded on a Shimadzu 2450 UV-vis spectrophotometer at RT. The steady-state emission spectra of the complexes dispersed in solvents were obtained using a Perkin-Elmer LS $50 \mathrm{~B}$ luminescence spectrometer at RT with excitation and emission band-pass of $2.5 \mathrm{~nm}$.

\section{X-ray crystallography}

Single crystal X-ray diffraction data of 1-6 were collected at $100 \mathrm{~K}$ on a Bruker SMART APEX CCD diffractometer using graphite-monochromated $\operatorname{MoK}_{\alpha}$ radiation $(\lambda=0.71073 \AA)$. The data reduction, structure solution and refinement were done as detailed earlier. ${ }^{32}$ In 6 , the $\mathrm{H}$ atoms of the coordinated water molecules could not be located in the difference Fourier maps. In all the cases, the $\mathrm{H}$ atoms attached to $\mathrm{C}$ atoms were positioned geometrically and treated as riding atoms using SHELXL default parameters. Several DFIX commands were used for fixing a few bond distances in 2-6. Except in 3 and 4, the disordered solvent molecules could not be located in the successive difference Fourier maps and hence the PLATON $^{33}$ squeeze method was used. The number of guest molecules present in the complexes was confirmed by the combination of thermogravimetric (TG) and elemental analyses. The crystal and refinement data for 1-6 are collected in Table $\mathrm{S} 1 \uparrow$ while selective bond distances and angles are given in Table S2.†

\section{Synthesis of the ligands}

Details of the synthetic procedure for the ligand $\mathbf{H}_{2} \mathbf{L}$ and its characterization are given in the ESI. $\dagger$ The co-ligand azpy was synthesized following a literature procedure. ${ }^{34}$

\section{Synthesis of the complexes}

$\left\{\left[\mathrm{Zn}(\mathrm{L})(\mathrm{azpy})_{0.5}\right]\left(0.5 \mathrm{H}_{2} \mathrm{O}\right)\right\}_{n}$ (1). This complex was synthesized by mixing $\mathbf{H}_{2} \mathbf{L}(0.037 \mathrm{~g}, 0.1 \mathrm{mmol})$, azpy (0.018 g, 0.1 $\mathrm{mmol}), \mathrm{Zn}\left(\mathrm{NO}_{3}\right)_{2} \cdot 6 \mathrm{H}_{2} \mathrm{O}(0.06 \mathrm{~g}, 0.2 \mathrm{mmol})$, DMF $(2 \mathrm{~mL})$ and $\mathrm{H}_{2} \mathrm{O}(1 \mathrm{~mL})$ in a Teflon-lined autoclave, and heating under autogenous pressure at $90{ }^{\circ} \mathrm{C}$ for $72 \mathrm{~h}$ followed by slow cooling to room temperature. The resulting orange-colored block-shaped crystals were isolated by filtration in $\sim 45 \%$ yield based on $\mathrm{H}_{2} \mathrm{~L}$. Anal. calcd. for $\mathrm{C}_{27} \mathrm{H}_{21} \mathrm{~N}_{2} \mathrm{O}_{6.5} \mathrm{Zn:} \mathrm{C}, 59.74$; $\mathrm{H}, 3.9$; N, 5.16\%. Found: C, 60.15; H, 3.35; N, 5.97\%. IR $\left(\mathrm{cm}^{-1}\right)$ : 3430(br), 2936(s), 1632(s), 1597(s), 1514(s), 1407(m), 1354(m), 1265(s), 1230(s), 1140(s), 1035(s), 850(s), 760(s).

$\left\{\left[\mathrm{Zn}_{2}(\mathrm{~L})_{2}(\operatorname{azpy})\right](\mathrm{DMF})\left(\mathbf{1 . 5 H _ { 2 }} \mathrm{O}\right)\right\}_{n}$ (2). Compound 2 was synthesized by mixing $\mathbf{H}_{2} \mathbf{L}(0.037 \mathrm{~g}, 0.1 \mathrm{mmol})$, azpy $(0.018 \mathrm{~g}$, $0.1 \mathrm{mmol}), \mathrm{Zn}\left(\mathrm{NO}_{3}\right)_{2} \cdot 6 \mathrm{H}_{2} \mathrm{O}$ (0.06 g, $\left.0.2 \mathrm{mmol}\right), \mathrm{DMF}(2 \mathrm{~mL})$ and $\mathrm{H}_{2} \mathrm{O}(1 \mathrm{~mL})$ in a Teflon-lined autoclave, and heating under autogenous pressure at $120{ }^{\circ} \mathrm{C}$ for $72 \mathrm{~h}$ followed by slow cooling to room temperature. Orange-colored blockshaped crystals were isolated by filtration in $\sim 15 \%$ yield based on $\mathrm{H}_{2}$ L. Anal. calcd. for $\mathrm{C}_{57} \mathrm{H}_{50} \mathrm{~N}_{5} \mathrm{O}_{14.5} \mathrm{Zn}_{2}$ : C, 58.62; $\mathrm{H}$, 4.32; N, 6.00\%. Found: C, 59.35; H, 4.19; N, 6.20\%. IR $\left(\mathrm{cm}^{-1}\right)$ : 3558(br), 3440(br), 3054(br), 2930(br), 2830(br), 1680(s), 1620(s), 1526(s), 1400(s), 1235(m), 1195(m), 1165(s), 1080(s), $850(\mathrm{~s}), 780(\mathrm{~s})$.

$\{[\mathbf{Z n}(\mathbf{L})(\text { bphy })](\mathrm{DMF})\}_{n}$ (3). This compound was synthesized as in the case of 1 except that heating was done at 140 ${ }^{\circ} \mathrm{C}$ for $72 \mathrm{~h}$ followed by slow cooling to room temperature. Colorless rectangular parallelepiped crystals of 3 were isolated by filtration in $\sim 45 \%$ yield (based on $\mathrm{H}_{2} \mathrm{~L}$ ). Anal. calcd. For $\mathrm{C}_{35} \mathrm{H}_{33} \mathrm{~N}_{5} \mathrm{O}_{7} \mathrm{Zn}$ : C, 59.97; $\mathrm{H}, 4.74 ; \mathrm{N}, 9.99 \%$. Found: C, 58.85; H, 4.95; N, 9.47\%. IR $\left(\mathrm{cm}^{-1}\right)$ : 3430(br), 3137(br), 2929(s), 2847(s), 1686(s), 1597(m), 1520(s), 1366(s), 1200(s), 1165(m), 1016(s), 827(s), 720(s).

$\left[\mathrm{Cd}(\mathrm{L})(\operatorname{azpy})_{0.5}(\mathrm{DMF})\left(\mathrm{H}_{2} \mathrm{O}\right)\right]_{n}$ (4). A mixture of $\mathrm{H}_{2} \mathrm{~L}(0.037 \mathrm{~g}$, $0.1 \mathrm{mmol})$, azpy $(0.018 \mathrm{~g}, 0.1 \mathrm{mmol}), \mathrm{Cd}\left(\mathrm{NO}_{3}\right)_{2} \cdot 4 \mathrm{H}_{2} \mathrm{O}(0.062 \mathrm{~g}$, $0.2 \mathrm{mmol})$, DMF $(2 \mathrm{~mL})$ and $\mathrm{H}_{2} \mathrm{O}(1 \mathrm{~mL})$ were sealed in a Teflon-lined autoclave, heating under autogenous pressure to $90{ }^{\circ} \mathrm{C}$ for $72 \mathrm{~h}$ followed by slow cooling to room temperature. The desired compound was isolated by filtration as orange block-shaped crystals in $\sim 55 \%$ yield. Anal. calcd. for $\mathrm{C}_{30} \mathrm{H}_{29} \mathrm{~N}_{3} \mathrm{O}_{8} \mathrm{Cd}$ : C, 53.63; H, 4.35; N, 6.25\%. Found: C, 53.06; $\mathrm{H}, 4.52 ; \mathrm{N}, 6.36 \%$. IR $\left(\mathrm{cm}^{-1}\right)$ : 3232(br), 2924(br), 1662(s), 1609(s), 1585(s), 1390(m), 1241(m), 1194(s), 1028(s), 844(s), $785(\mathrm{~s})$.

$\left\{[\mathrm{Co}(\mathrm{L})(\operatorname{azpy})]\left(2 \mathrm{H}_{2} \mathrm{O}\right)\right\}_{n}(5)$. The synthesis of 5 was achieved as in the case of 4 taking $\mathrm{Co}\left(\mathrm{NO}_{3}\right)_{2} \cdot 6 \mathrm{H}_{2} \mathrm{O}$ in place of $\mathrm{Cd}\left(\mathrm{NO}_{3}\right)_{2} \cdot 4 \mathrm{H}_{2} \mathrm{O}$ and heating under autogenous pressure at 90 ${ }^{\circ} \mathrm{C}$ for $72 \mathrm{~h}$ followed by slow cooling to room temperature. The resulting pink-colored block-shaped crystals were isolated by filtration in $\sim 55 \%$ yield. Anal. calcd. For $\mathrm{C}_{27} \mathrm{H}_{24} \mathrm{~N}_{2} \mathrm{O}_{8} \mathrm{Co}$ : C, 57.56; H, 4.29; N, 4.97\%. Found: C, 57.89; H, 4.44; N, 4.36\%. IR $\left(\mathrm{cm}^{-1}\right)$ : 3433(br), 2924(br), 2831(br), 1609(s), 1555(m), 1520(s), $1407(\mathrm{~s}), 1200(\mathrm{~s}), 1022(\mathrm{~s}), 856(\mathrm{~s}), 780(\mathrm{~s})$.

$\left\{\left[\mathrm{Co}_{3}(\mathrm{~L})_{2}(\mathrm{bphy})_{2}(\mathrm{HCOO})_{2}\left(\mathrm{H}_{2} \mathrm{O}\right)_{2}\right](6 \mathrm{DMF})\left(6 \mathrm{H}_{2} \mathrm{O}\right)\right\}_{n} \quad$ (6). The synthesis of this compound was achieved following the above procedure except heating at $140{ }^{\circ} \mathrm{C}$ for $72 \mathrm{~h}$ followed by slow cooling to room temperature. The resulting pink-colored block-shaped crystals were isolated by filtration in $\sim 10 \%$ yield. Anal. calcd. for $\mathrm{C}_{84} \mathrm{H}_{112} \mathrm{~N}_{14} \mathrm{O}_{30} \mathrm{Co}_{3}: \mathrm{C}, 51.09 ; \mathrm{H}, 5.72 ; \mathrm{N}$, 9.93\%. Found: C, 52.01; H, 6.15; N, 10.16\%. IR $\left(\mathrm{cm}^{-1}\right)$ : 3439(br), 3060(br), 2912(br), 1656(s), 1602(s), 1578(s), 1507(s), 1400(s), 1347(s), 1253(m), 1176(s), 867(s), 791(s).

\section{Results and discussion}

Once isolated, 1-6 are found to be stable in air and insoluble in water and common organic solvents. The IR spectra (Fig. S7-S12 $\dagger$ ) of all the complexes show strong absorption bands in the range of $1400-1600 \mathrm{~cm}^{-1}$ attributable to coordinated carboxylate groups. ${ }^{35}$ Broad bands in the region of 3230-3560 $\mathrm{cm}^{-1}$ indicate the presence of lattice and coordinated water molecules. ${ }^{36}$ Sharp peaks between 1640 and $1690 \mathrm{~cm}^{-1}$ are 
indicative of the presence of DMF molecules. ${ }^{37}$ The peak in the range of $1609-1632 \mathrm{~cm}^{-1}$ corresponds to the presence of $-\mathrm{N}=\mathrm{N}-$ in the framework. ${ }^{38}$

Complexes 1 and 2 crystallize in the triclinic space group $P \overline{1}$ (Table S1 $\dagger$ ). Both structures contain paddle-wheel $\mathrm{Zn}_{2}(\mathrm{COO})_{4}$ clusters as the secondary building unit (SBU) where each $\mathrm{Zn}^{2+}$ ion adopts a distorted square-pyramidal coordination. The equatorial positions are occupied by the carboxylate $\mathrm{O}$ atoms from four different $\mathbf{L}^{-2}$ (hereafter, $\mathbf{L}$ ) linkers and the apical position is occupied by a $\mathrm{N}$ atom of azpy co-linker (Fig. 1). All the $\mathrm{Zn}-\mathrm{O}$ and $\mathrm{Zn}-\mathrm{N}$ bond distances are comparable to the values in the existing literature. ${ }^{39}$

The binding mode of the carboxylate groups of $\mathbf{L}$ and the $\mathrm{N}$ atom of azpy to the metal centre $\left(\mu_{4}: \eta^{1}: \eta^{1}: \eta^{1}: \eta^{1}\right.$ and $\mu_{2}: \eta^{1}: \eta^{1}$, respectively) is the same for both 1 and 2 (Fig. S13a, $\mathrm{b}$ and $\mathrm{g} \dagger$ ). This connectivity pattern leads to two-fold interpenetrated 2D layers in each case (Fig. 2). Topological simplification with the Topos software ${ }^{40}$ shows an $s q l$ topology (4-c uninodal net) with point symbol $\left\{4^{4} \cdot 6^{2}\right\}$ (Fig. S14 and S15†).

Although both 1 and 2 exhibit the same binding mode of the linker and the co-linker, careful examination of the structures reveal that they constitute a pair of orientation isomers (Fig. 1). In 1, a number of $\mathrm{C}-\mathrm{H} \cdots \pi$ interactions (Table $\mathrm{S} 3 \dagger$ ) exist among the $\mathrm{H}$ atoms of the $-\mathrm{OCH}_{3}$ group of $\mathrm{L}$ of one 2D layer with the aromatic $\pi$ orbitals (ring a or c, Fig. 1) of another layer. These non-bonding interactions are present in 2 as well. In 1, the aromatic ring of the azpy co-linker from the nearby layer is also involved in the $\mathrm{C}-\mathrm{H} \cdots \pi$ interactions with the $-\mathrm{OCH}_{3}$ group. However, this is absent in 2 (Fig. 3). Additionally, the interpenetrated layers in 2 show $\mathrm{C}-\mathrm{H} \cdots \pi$ interactions between the middle ring ( $\operatorname{ring} \mathbf{b}$ ) of $\mathbf{L}$ and the $-\mathrm{OCH}_{3}$ group (Fig. 4), which is absent in 1. All these interactions (Fig. S16c and $\mathrm{d} \dagger$ ) are responsible for the formation of the orientation isomers.

Complex 3 is formed under a solvothermal reaction temperature of $140{ }^{\circ} \mathrm{C}$ where the $-\mathrm{N}=\mathrm{N}$ - group in the co-linker azpy undergoes in situ reduction to - $\mathrm{NH}-\mathrm{NH}-$ (bphy). It crystallizes in the orthorhombic space group Pbca (Table S1†) with the asymmetric unit consisting one $\mathrm{Zn}$ (II) ion, one $\mathbf{L}$

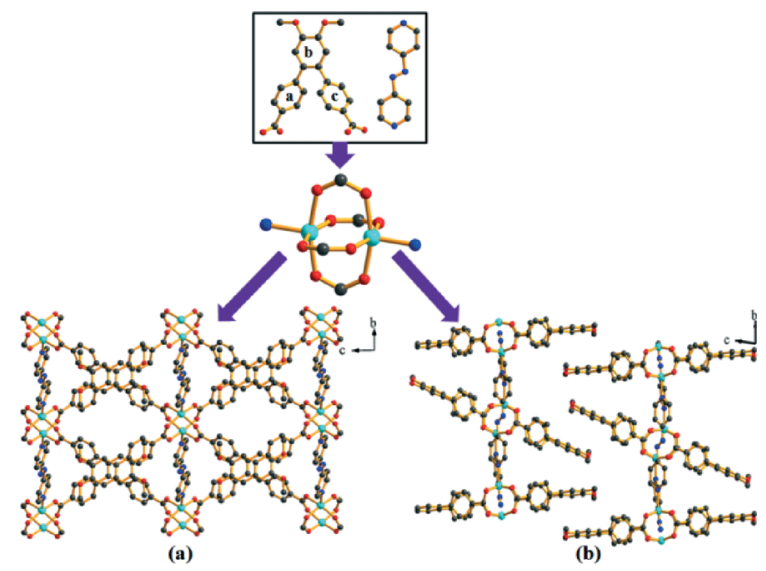

Fig. 1 Metal-linker connectivity leads to isomeric complexes (a) 1 and (b) $\mathbf{2}$ as viewed along the a-axis ( $\mathrm{H}$ atoms are omitted for clarity).

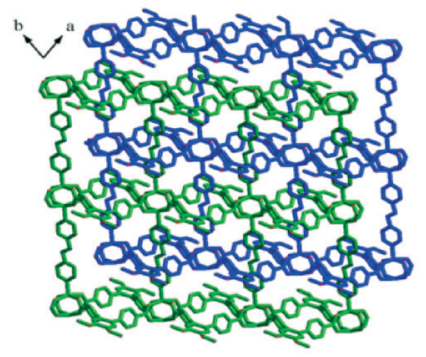

(a)

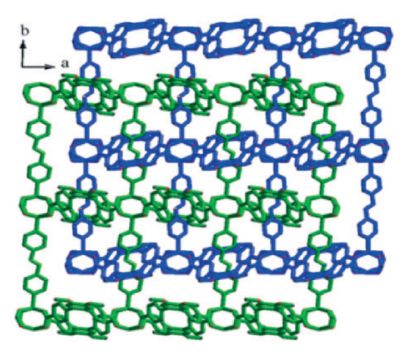

(b)
Fig. 2 Two-fold interpenetrated 2D layers of (a) 1 and (b) 2 viewed along the $c$-axis.

linker, one bphy co-linker and one DMF molecule in the cavity (Fig. S17a†). The metal ion assumes a distorted tetrahedral coordination geometry (Fig. 5a) with ligation by two pyridine $\mathrm{N}$ atoms and two monodentate carboxylate $\mathrm{O}$ atoms.

The $\mathrm{C}-\mathrm{N}-\mathrm{N}-\mathrm{C}$ torsion angle in 3 is $106.22(65)^{\circ}$ which indicates its deviation from the planar configuration of $-\mathrm{C}-\mathrm{N}=\mathrm{N}-\mathrm{C}-$ in azpy (nearly $180^{\circ}$ ) (Table S4 $\uparrow$ ). The mode of binding of carboxylates and bphy ligands are: $\mu_{2}: \eta^{1}: \eta^{0}: \eta^{1}: \eta^{0}$ and $\mu_{2}: \eta^{1}: \eta^{1}$, respectively (Fig. S13c and $h \dagger$ ). In 3, the bphy unit propagates along the $b$-axis and forms a 1D parallel chain that is connected by $\mathbf{L}$ leading to a $2 \mathrm{D}$ structure (Fig. S17b and c $\dagger$ ). A number of non-covalent interactions (Fig. 5b) between these 2D layers lead to an overall 3D architecture. Topological simplification shows an $s q l$ topology (Fig. S18†).

Complex 4 crystallizes in the triclinic space group $P \overline{1}$ (Table S1 $\uparrow$ ). The asymmetric unit consists of one $\mathrm{Cd}(\mathrm{II})$ ion, one $\mathbf{L}$ unit, half of an azpy ligand, one coordinated water and DMF molecule (Fig. S19a†). The $\mathrm{Cd}^{2+}$ ion is heptacoordinated with ligation by four $\mathrm{O}$ atoms of two bidentate carboxylates, one $\mathrm{N}$ atom of azpy and two $\mathrm{O}$ atoms of water and DMF molecules (Fig. S19b†). All $\mathrm{Cd}-\mathrm{O}$ and $\mathrm{Cd}-\mathrm{N}$ bond distances (Table S2 $\dagger$ ) are comparable to those reported earlier. $^{32}$
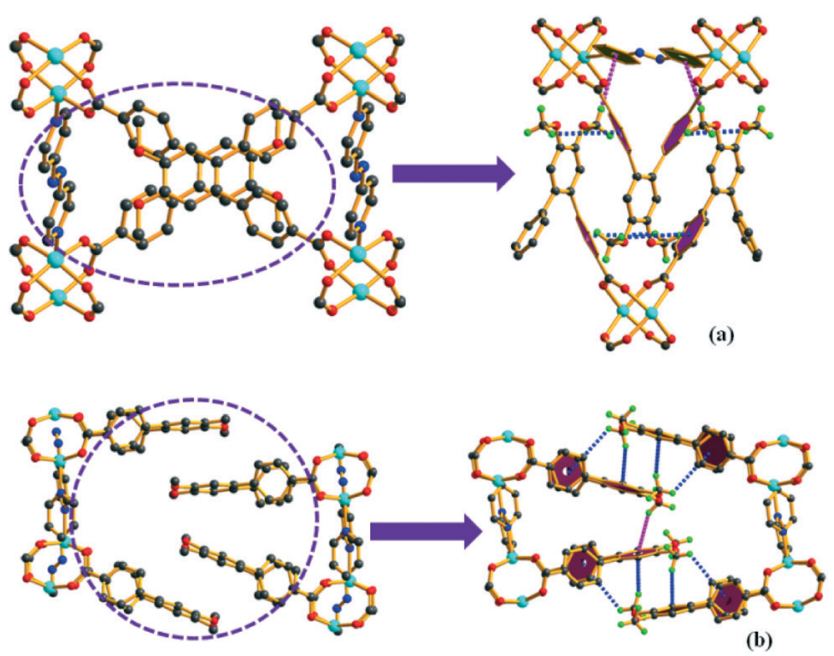

Fig. 3 The perspective view of the $\mathrm{C}-\mathrm{H} \cdots \pi$ interactions in complex 1 (a) and 2 (b). 


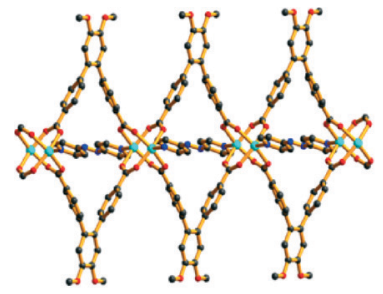

(a)

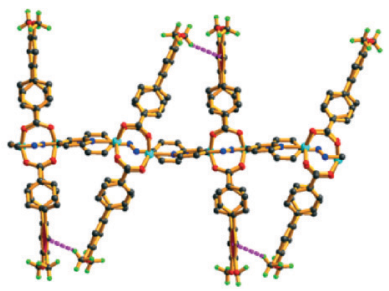

(b)
Fig. 4 The $\mathrm{C}-\mathrm{H} \cdots \pi$ interactions (pink dotted lines) between two interpenetrated layers present in $\mathbf{2}$ (b) is absent in 1 (a).

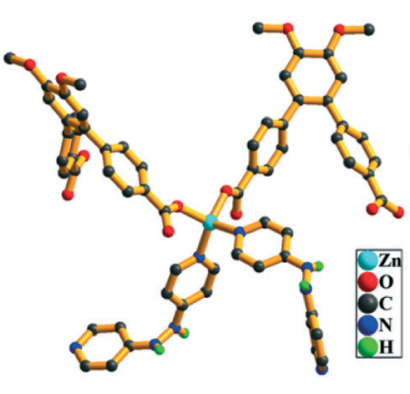

(a)

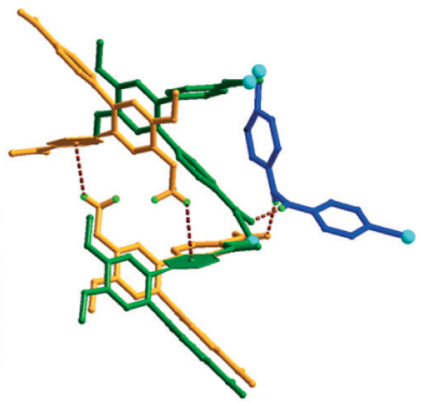

(b)
Fig. 5 (a) The perspective view of the coordination environment around the $\mathrm{Zn}(\mathrm{II})$ center, (b) the dotted lines represent the $\mathrm{C}-\mathrm{H} \cdots \pi$ and hydrogen bonding interactions.

The carboxylate and the azpy ligands bind to the metal ion in $\mu_{2}: \eta^{1}: \eta^{1}: \eta^{1}: \eta^{1}$ and $\mu_{2}: \eta^{1}: \eta^{1}$ modes, respectively (Fig. S13d and $\mathrm{g} \dagger$ ). Each $\mathbf{L}$ binds to a Cd(II) ion in a bidentate fashion at either end. Each metal ion is further connected to the $\mathrm{N}$ atoms of azpy to form a 1D structure (Fig. 6). These 1D chains are interconnected by strong H-bonding interactions between the coordinated water molecule and carboxylates besides and $\mathrm{C}-\mathrm{H} \cdots \pi$ interactions between the $\mathrm{H}$ atom of $-\mathrm{OCH}_{3}$ group and the $\pi$ orbitals of the middle phenyl ring (ring b) of the nearest $\mathbf{L}$ ligand to form an overall 3D structure (Fig. S19†).

Complex 5 crystallizes in the monoclinic space group $C 2 / m$ (Table S1 $\dagger$ ). The asymmetric unit comprises one $\mathbf{L}$ linker (half occupancy), one Co(II) ion (half occupancy) and one azpy co-linker (half occupancy) (Fig. S20a†). The structure contains paddle-wheel $\mathrm{Co}_{2}(\mathrm{COO})_{4}$ clusters as the $\mathrm{SBU}$, where the Co $\cdots$ Co distance is approximately $2.713(1) \AA$. Each Co(II) ion adopts a distorted square-pyramidal coordination geometry with equatorial ligation by carboxylate $\mathrm{O}$ atoms from four

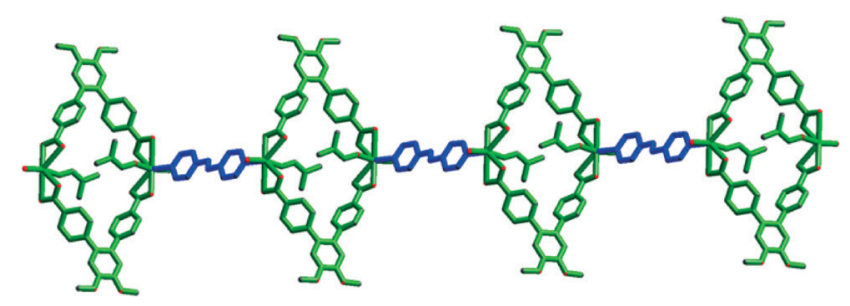

Fig. 6 One dimensional chain of 4 . different $\mathbf{L}$ units and the axial site is occupied by one $\mathbf{N}$ atom from an azpy molecule (Fig. S20b $\dagger$ ). The binding pattern of the carboxylate group of $\mathbf{L}$ and azpy to the metal centre are: $\mu_{4}: \eta^{1}: \eta^{1}: \eta^{1}: \eta^{1}$ and $\mu_{2}: \eta^{1}: \eta^{1}$, respectively (Fig. S13e and $g \dagger$ ) and that forms a 2D layer structure (Fig. S20c $\dagger$ ). These layers are further involved in the $\mathrm{C}-\mathrm{H} \cdots \pi$ interactions (Table $\mathrm{S} 3 \dagger$ ) between the $\mathrm{H}$ atom of the $-\mathrm{OCH}_{3}$ group and the $\pi$-orbitals of the phenyl rings of the azpy co-linker to form an overall 3D architecture (Fig. 7). All the Co-O and Co-N bond distances are comparable to those reported earlier (Table S2 $\dagger$ ). ${ }^{41}$ Complex 5 also exhibits an $\boldsymbol{s q l}$ topology (Fig. S21†).

Compound 6 crystallizes in the monoclinic space group $P 2_{1} / c$ (Table S1 $\dagger$ ). The asymmetric unit contains two crystallographically independent $\mathrm{Co}$ (II) ions (Co1 half and Co2 full occupancy), one $\mathbf{L}$ and one bphy ligand, one coordinated formate and one coordinated water (Fig. S22 $\dagger$ ). In situ reduction of the azpy co-linker to bphy and hydrolysis of DMF to formate take place as the solvothermal reaction temperature is raised to $140{ }^{\circ} \mathrm{C} .{ }^{42}$

As shown in Fig. 8, the structure contains a centrosymmetric $\left[\mathrm{Co}_{3}{ }_{3}\right]^{6+}$ trimeric core where each metal is hexacoordinated. The middle $\mathrm{Co}(\mathrm{II})$ ion is ligated by four $\mathrm{O}$ atoms from four different $\mathbf{L}$ ligands and two $\mathrm{O}$ atoms from two bridging formate anions. Each terminal metal ion is coordinated by two $\mathrm{O}$ atoms from two different $\mathrm{L}$ ligands, two $\mathrm{N}$ atoms from two bphy ligands, one $\mathrm{O}$ atom from a water molecule and one $\mathrm{O}$ atom from one bridging formate anion. The reduction of the azo group has been confirmed by the $\mathrm{N}-\mathrm{N}$ bond length and the $-\mathrm{C}-\mathrm{N}-\mathrm{N}-\mathrm{C}-$ torsion angle (Table S4 $\dagger$ ). The binding modes of carboxylate and bphy ligands towards the metal ions are:

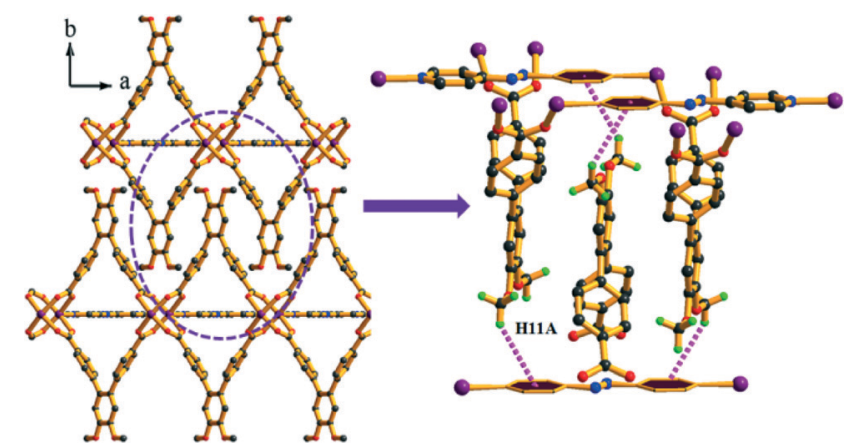

Fig. 7 The presence of $\mathrm{C}-\mathrm{H} \cdots \pi$ interaction of 5 in crystallographic $c$ direction.

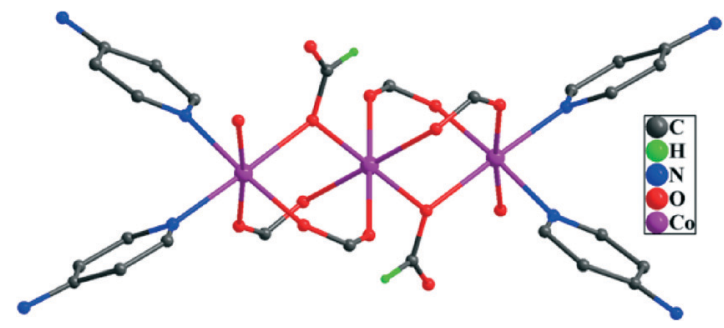

Fig. 8 Coordination environment around the Co(II) trimeric unit. 
$\mu_{4}: \eta^{1}: \eta^{1}: \eta^{1}: \eta^{1}$ and $\mu_{2}: \eta^{1}: \eta^{1}$, respectively (Fig. S13f and $h \dagger$ ). These connectivity patterns lead to the formation of a 2D layer structure (Fig. 9) with an sql topology (Fig. S23†).

\section{PXRD and thermal stability}

The phase purity of 1-6 can be confirmed by using powder $\mathrm{X}$-ray diffraction (PXRD) patterns, which are in excellent agreement with the corresponding simulated patterns (Fig. S24-S29†).

The TG curve of 1 shows a gradual weight loss of $1.48 \%$ (calcd. 1.65\%) due to the removal of lattice water molecules in the temperature range of $30-100{ }^{\circ} \mathrm{C}$. The framework is stable at least up to $385{ }^{\circ} \mathrm{C}$ (Fig. S30 $\dagger$ ). The TG curve of 2 exhibits a weight-loss of $2.1 \%$ till $110^{\circ} \mathrm{C}$ attributable to the loss of lattice water molecules (calcd. 2.3\%). Further heating leads to a rapid weight-loss of $6 \%$ in the range of $115-170{ }^{\circ} \mathrm{C}$ due to the loss of lattice DMF molecules (calcd. 6.26\%). Decomposition of the compound is achieved beyond $380{ }^{\circ} \mathrm{C}$ (Fig. S31†). Complex 3 shows a weight loss of $10.30 \%$ corresponding to the loss of cavity DMF molecules (calcd. 10.40\%) within 160 to $240{ }^{\circ} \mathrm{C}$ and after $355{ }^{\circ} \mathrm{C}$ it starts to decompose (Fig. S32 $\dagger$ ). Complex 4 releases its coordinated water (obsd. 2.7\%; calcd. 2.6\%) and DMF molecule (obsd. 10.5\%; calcd. $11.16 \%$ ) in the range of 95 to $105{ }^{\circ} \mathrm{C}$ and 175 to $205{ }^{\circ} \mathrm{C}$, respectively and decomposition occurs after $360{ }^{\circ} \mathrm{C}$ (Fig. S33†). The TG curve of 5 displays gradual removal of its lattice water molecules (obsd. 5.6\%; calcd. 5.48\%) up to $130{ }^{\circ} \mathrm{C}$ and it decomposes after $380^{\circ} \mathrm{C}$ (Fig. S34†). Complex 6 releases the lattice and coordinated water molecules in the range of 70 to $110{ }^{\circ} \mathrm{C}$ (obsd. 8.1\%; calcd. 7.29\%) and free DMF molecules up to $180{ }^{\circ} \mathrm{C}$ (obsd. $24.2 \%$; calcd. $22.11 \%$ ). Decomposition of this compound is achieved beyond $390{ }^{\circ} \mathrm{C}$ (Fig. S35†).

\section{Photoluminescence properties}

Photoluminescence studies of coordination polymers with $\mathrm{d}^{10}$ metal ions and conjugated ligands consisting of nitrogen and carboxylate donors have been a subject of investigation due to their potential applications ${ }^{43,44}$ in non-linear optics, sensors, photocatalysis and so on. Therefore, solid state

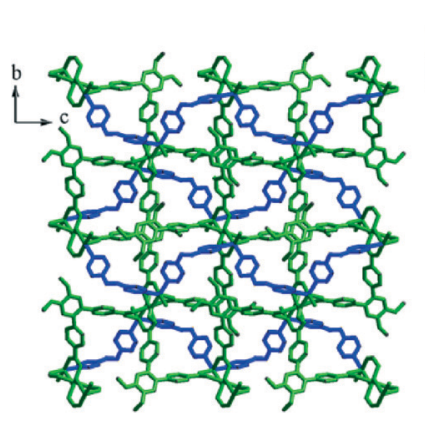

(a)

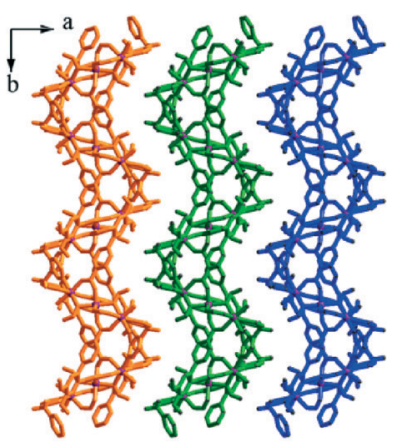

(b)
Fig. 9 (a) View of a 2D layer in 6 as viewed along the a axis and (b) an overall structure of 6 as viewed along the $c$ axis.

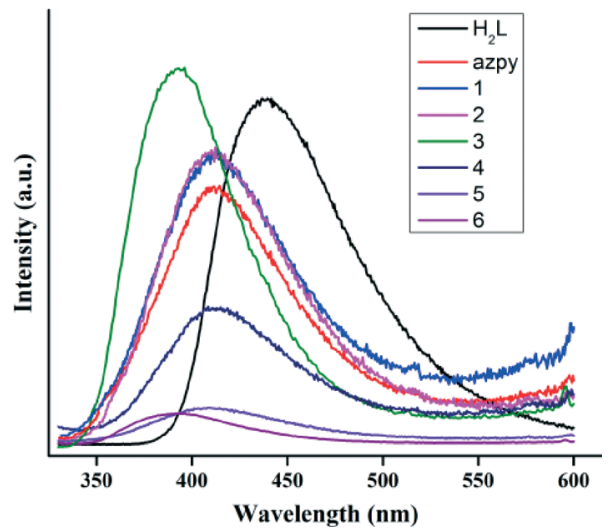

Fig. 10 Emission spectra of $\mathrm{H}_{2} \mathrm{~L}$, azpy and 1-6 in solid state at room temperature.

luminescence properties of complexes 1-4 along with 5 and 6, free $\mathrm{H}_{2} \mathrm{~L}$ and azpy are studied at room temperature. As shown in Fig. 10, the metal-free $\mathbf{H}_{2} \mathrm{~L}$ shows an emission maximum at $450 \mathrm{~nm}$ upon excitation at $315 \mathrm{~nm}$. On the other hand, metal-free azpy gives an emission at $412 \mathrm{~nm}$ upon excitation at $310 \mathrm{~nm}$. The nature of the emission profiles of all the complexes except 3 and 6 resembled free azpy without any change of the emission maximum. Therefore, the nature of this emission is attributable to the intra-ligand $n-\pi^{*}$ or $\pi-\pi^{*}$ transition of azpy. The complexes with $\mathrm{d}^{10}$ metal ions, emission through metal-to-ligand or ligand-to-metal charge transfer is less probable due to difficulty in oxidation or reduction. ${ }^{45,46}$ Complexes 1, 2, 4 and 5 show a similar emission behaviour with a decrease in emission intensity compared to that of the free ligand probably due to the quenching effect of the water molecules present in the frameworks. ${ }^{47,48}$ For complex 5, the presence of the paramagnetic $\mathrm{Co}(\mathrm{II})$ ion can be a probable reason for its very low emission intensity. ${ }^{49,50}$

When azpy is in situ reduced to bphy, the $\pi$-conjugation is diminished and the energy gap between excited and ground states of bphy become higher than that in azpy, giving emission maxima at shorter wavelengths ${ }^{51}$ (392 and $386 \mathrm{~nm}$ for 3 and 6 , respectively, $\lambda_{\mathrm{ex}}=340 \mathrm{~nm}$ ), which can be attributed to the intra-ligand transition of the bphy ligand. The luminescence enhancement in 3 can result from the increased rigidity of the ligand upon metal coordination which reduces nonradiative decay. ${ }^{52}$ For 6 , the fall in intensity is due to $\mathrm{Co}$ (II) as well as the vibrational quenching of water present in the framework. The emission spectra of 1-4 dispersed in solvents of different polarity (DMF, ethanol and hexane) do not show any significant shift of the emission bands obtained in the solid-state (Fig. S36†).

\section{Conclusions}

Six metal organic frameworks have been synthesized by the solvothermal reaction of a rationally designed V-shaped linker $\mathbf{H}_{2} \mathbf{L}$ and co-linker azpy with different metal ions at 
different temperatures. Among them, 1 and 2 exhibit temperature-dependent framework orientational isomerism due to the presence of different $\mathrm{C}-\mathrm{H} \cdots \pi$ interactions between two adjacent 2D layers which is a rare observation. Employment of a higher temperature leads to the in situ reduction of azpy ligand to the flexible bphy to afford 3 and 6, respectively. The room temperature photoluminescence properties were studied in solid-state. The successful synthesis of these complexes (1-6) improves the idea of crystal engineering which can help us to design ligands for the synthesis of coordination polymers endowed with interesting properties.

\section{Acknowledgements}

We gratefully acknowledge the financial support from the Department of Science and Technology, New Delhi, India (to P. K. B.) and SRF from the CSIR to S. P. and T. K. P.

\section{Notes and references}

1 N. L. Rosi, J. Eckert, M. Eddaoudi, D. T. J. Kim, M. O'Keefe and O. M. Yaghi, Science, 2003, 300, 1127-1129.

2 K. Biradha, A. Ramanan and J. J. Vittal, Cryst. Growth Des., 2009, 9, 2969-2970.

3 A. Santra, I. Senkovska, S. Kaskel and P. K. Bharadwaj, Inorg. Chem., 2013, 52, 7358-7366.

4 C. He, K. Lu, D. Liu and W. Lin, J. Am. Chem. Soc., 2014, 136, 5181-5184.

5 A. Aijaz, T. Akita, N. Tsumori and Q. Xu, J. Am. Chem. Soc., 2013, 135, 16356-16359.

6 D. De, T. K. Pal, S. Neogi, S. Senthilkumar, D. Das, S. S. Gupta and P. K. Bharadwaj, Chem. - Eur. J., 2016, DOI: 10.1002/chem.201504747.

7 S. S. Nagarkar, S. M. Unni, A. Sharma, S. Kurungot and S. K. Ghosh, Angew. Chem., Int. Ed., 2014, 53, 2638-2642.

8 N. Stock and S. Biswas, Chem. Rev., 2012, 112, 933-969.

9 J. L. Atwood, L. J. Barbour and A. Jerga, Angew. Chem., Int. Ed., 2004, 43, 2948-2950.

10 Z. Su, J. A. Fan, M. Chen, T. Okamura and W. Y. Sun, Cryst. Growth Des., 2011, 11, 1159-1169.

11 C. N. Morrison, A. K. Powell and G. E. Kostakis, Cryst. Growth Des., 2011, 11, 3653-3662.

12 Q. A. Zhang, J. Y. Zhang, Q. Y. Yu, M. Pan and C. Y. Su, Cryst. Growth Des., 2010, 10, 4076-4084.

13 A. Santra and P. K. Bharadwaj, Cryst. Growth Des., 2014, 14, 1476-1485.

14 Y.-B. Dong, Y.-Y. Jiang, J. Li, J.-P. Ma, F.-L. Liu, B. Tang, R.-Q. Huang and S. R. Batten, J. Am. Chem. Soc., 2007, 129, 4520-4521.

15 S. Masaoka, D. Tanaka, Y. Nakanishi and S. Kitagawa, Angew. Chem., Int. Ed., 2004, 43, 2530-2534.

16 P. Cui, J. Dou, D. Sun, F. Dai, S. Wang, D. Sun and Q. Wu, CrystEngComm, 2011, 13, 6968-6971.

17 M. V. Narinho, M. I. Yoshida, K. J. Guedes, K. Krambrock, A. J. Bortoluzzi, M. Horner, F. C. Machado and W. M. Teles, Inorg. Chem., 2004, 43, 1539-1544.
18 G. B. Li, J. M. Liu, Z. Q. Yu, W. Wang and C. Y. Su, Inorg. Chem., 2009, 48, 8659-8661.

19 T. A. Makal, A. A. Yakovenko and H.-C. Zhou, J. Phys. Chem. Lett., 2011, 2, 1682-1689.

20 X. N. Zhao, H. He, F. Dai, D. Sun and Y. Ke, Inorg. Chem., 2010, 49, 8650-8652.

21 D. Sun, S. Ma, J. M. Simmons, J.-R. Li, D. Yuan and H.-C. Zhou, Chem. Commun., 2010, 46, 1329-1331.

22 L. Han, A. Qin, X.-Z. Yan, L.-P. Xu, J. Sun, L. Yu, H.-B. Chen and X. Zou, Cryst. Growth Des., 2013, 13, 1807-1811.

23 S. Ma, D. Sun, M. Ambrogio, J. A. Fillinger, S. Parkin and H.-C. Zhou, J. Am. Chem. Soc., 2007, 129, 1858-1859.

24 T. Panda, T. Kundu and R. Banerjee, Chem. Commun., 2013, 49, 6197-6199.

25 R. Reuter and H. A. Wegner, Chem. Commun., 2011, 47, 12267-12276.

26 X.-M. Liu, L.-H. Xie, J.-B. Lin, R.-B. Lin, J.-P. Zhang and X.-M. Chen, Dalton Trans., 2011, 40, 8549-8554.

27 Y.-L. Gai, F.-L. Jiang, K.-C. Xiong, L. Chen, D.-Q. Yuan, L.-J. Zhang, K. Zhou and M.-C. Hong, Cryst. Growth Des., 2012, 12, 2079-2088.

28 X.-M. Liu, R.-B. Lin, J.-P. Zhang and X.-M. Chen, Inorg. Chem., 2012, 51, 5686-5692.

29 J.-S. Guo, M.-J. Zhang, C.-J. Zhang, X.-M. Jiang, G.-C. Guo and J.-S. Huang, Inorg. Chem. Commun., 2013, 37, 206-210.

30 J.-S. Guo, G. Xu, X.-M. Jiang, M.-J. Zhang, B.-W. Liu and G.-C. Guo, Inorg. Chem., 2014, 53, 4278-4280.

31 J.-S. Guo, G. Xu, S.-H. Wang, M.-S. Wang, M.-J. Zhang, G.-C. Guo and J.-S. Huang, Inorg. Chem. Commun., 2014, 45, 108-111.

32 T. K. Pal, R. Katoch, A. Garg and P. K. Bharadwaj, Cryst. Growth Des., 2015, 15, 4526-4535.

33 A. L. Spek, PLATON, The University of Utrecht, Utrecht, The Netherlands, 1999.

34 O. Theilmann, W. Saak, D. Haase and R. Beckhaus, Organometallics, 2009, 28, 2799-2807.

35 K. Nakamoto, Infrared and raman spectra of inorganic and coordination compounds, Wiley and sons, New York, 5th edn, 1997.

36 D. Dobrzynska, L. B. Jerzykiewicz, J. Jezierska and M. Duczmal, Cryst. Growth Des., 2005, 5, 1945-1951.

37 T. K. Pal, D. De, S. Neogi and P. K. Bharadwaj, Inorg. Chem. Front., 2015, 2, 395-402.

38 B. Bhattacharya, D. Saha, D. K. Maity, R. Dey and D. Ghoshal, CrystEngComm, 2014, 16, 4783-4795.

39 T. K. Pal, S. Neogi and P. K. Bharadwaj, Chem. - Eur. J., 2015, 21, 16083-16090.

40 The network topology was evaluated by the program "TOPOS-4.0", see http://www.topos.ssu.samara.ru; V. A. Blatov, IUCr Comp. Comm. Newsl., 2006, 7, 4.

41 P. Lama, J. Mrozinski and P. K. Bharadwaj, Cryst. Growth Des., 2012, 12, 3158-3168.

42 (a) L. Xie, S. Liu, B. Gao, C. Zhang, C. Sun, D. Li and Z. Su, Chem. Commun., 2005, 2402-2404; (b) J.-J. Shen, M.-X. Li, Z.-X. Wang, C.-Y. Duan, S.-R. Zhu and X. He, Cryst. Growth Des., 2014, 14, 2818-2830. 
43 F. P. Doty, C. A. Bauer, A. J. Skulan, P. G. Grant and M. D. Allendorf, Adv. Mater., 2009, 21, 95-101.

44 B. Gole, A. K. Bar and P. S. Mukherjee, Chem. Commun., 2011, 47, 12137-12139.

45 L. Wen, Y. Li, Z. Lu, J. Lin, C. Duan and Q. Meng, Cryst. Growth Des., 2006, 6, 530-537.

46 L. P. Zhang, J. F. Ma, J. Yang, Y. Y. Pang and J. C. Ma, Inorg. Chem., 2010, 49, 1535-1550.

47 A. J. Lan, K. H. Li, H. H. Wu, L. Z. Kong, N. Nijem, D. H. Olson, T. J. Emge, Y. J. Chabal, D. C. Langreth, M. C. Hong and J. Li, Inorg. Chem., 2009, 48, 7165-7173.
48 F. F. Chen, Z. Q. Chen, Z. Q. Bian and C. H. Huang, Coord. Chem. Rev., 2010, 254, 991-1010.

49 H.-F. Zhu, J. Fan, T. Okamura, W.-Y. Sunand and N. Ueyama, Cryst. Growth Des., 2005, 5, 289-294.

50 K. J. Franz, N. Singh, B. Spingler and S. J. Lippar, Inorg. Chem., 2000, 39, 4081-4092.

51 J. D. Luo, J. L. Hua, J. G. Qin, J. Q. Cheng, Y. C. Shen, Z. H. Lu, P. Wang and C. Ye, Chem. Commun., 2001, 171-172.

52 S. L. Zheng, J. H. Yang, X. L. Yu, X. M. Chen and W. T. Wong, Inorg. Chem., 2004, 43, 830-838. 